\title{
Audit of outcome of an extracapsular cataract extraction and posterior chamber intraocular lens training course
}

\author{
Mahmoud B Alhassan, Fatima Kyari, Ibrahim B Achi, Chinenyem P Ozemela, \\ Adenike Abiose
}

\begin{abstract}
Background-A training course for cataract surgery with intraocular lens implantation was organised in April 1997 at the National Eye Centre, Kaduna, Nigeria. Operations were performed by six Nigerian consultant ophthalmologists under the supervision of two surgeons from Aravind Eye Hospital, India.

Methods-A total of 175 eyes with uncomplicated cataracts were operated on after careful selection. All but six patients had extracapsular cataract extraction with posterior chamber intraocular lens insertion during the training programme.

Results-The mean age of the patients at operation was 54.2 years. One hundred and forty five of the operated eyes $(85.8 \%)$ were blind before surgery of which six $(3.6 \%)$ remained blind postoperatively. An uncorrected visual acuity of $6 / 60$ or better was achieved in $\mathbf{8 7 . 3 \%}$ eyes after surgery. Forty one patients $(24.3 \%)$ were blind before surgery, two of whom $(1.2 \%)$ remained blind afterwards. The most common intraoperative complication was posterior capsular rent which occurred in 10 eyes (5.7\%); striate keratopathy/corneal oedema and cortical remnant were the most common immediate postoperative complications, occurring in $44.6 \%$ and $8.0 \%$, respectively.

Conclusion-With adequate surgical skills, extracapsular cataract extraction with posterior chamber intraocular lens implantation offers good visual rehabilitation even under training conditions. (Br f Ophthalmol 2000;84:848-851)
\end{abstract}

Cataract continues to be the major cause of blindness worldwide and the major cause of treatable blindness in Nigeria, accounting for about $50 \%$ of blind patients. ${ }^{1}$ This burden is expected to increase with increased life expectancy and the growing aged population in Africa.

Department of Clinical

Ophthalmology,

National Eye Centre,

PMB 2267, Kaduna,

Nigeria

M B Alhassan

F Kyari

I B Achi

C P Ozemela

A Abiose

Correspondence to:

Dr M B Alhassan

Accepted 3 May 2000 ment of cataracts in industrialised countries.

In Nigeria there has been a gradual conversion towards extracapsular cataract extraction
(ECCE) with posterior chamber intraocular lens implantation (PC-IOL). The major obstacle to this has been the dearth of trained staff and affordable intraocular lenses. The situation is similar in many of the sub-Saharan countries of Africa. In the Democratic Republic of Congo (formerly Zaire), for example, only two national ophthalmologists have skills in IOL microsurgery. ${ }^{3}$ A decision was taken to train trainers in microsurgical skills and IOL implantation to make PC-IOL surgery available in Nigeria.

IOL microsurgery was first introduced in the National Eye Centre (NEC), Kaduna, Nigeria in 1993 by one surgeon who had received the necessary training abroad. His early experience and difficulties have been reported elsewhere. ${ }^{4}$

NEC, a World Health Organisation (WHO) collaborating centre for the prevention of blindness, is a tertiary eye hospital located in the suburbs of Kaduna in Nigeria. There are facilities for keratometry, A-scan biometry, and microsurgery.

This paper describes the outcome of surgery carried out during the first ECCE + PC-IOL training course conducted at NEC for six consultant ophthalmologists. The intraoperative and immediate postoperative complications and the short term visual outcome are reported.

\section{Materials and methods}

Patients with uncomplicated cataracts were selected for the training course, which took place in April 1997. Preoperative assessment included visual acuity (VA) testing with Snellen's or illiterate E charts, slit lamp biomicroscopy, and dilated funduscopy. Keratometry and A-scan biometry were performed to determine the IOL power using the SRK formula.

Training consisted of wet laboratory microsurgical practice followed by stepped surgery, initially under close supervision, loose supervision and, later, independent surgery, all under local anaesthesia. Six consultant ophthalmologists from various teaching institutions participated in the training under the supervision of two experienced Indian ophthalmologists.

The operations were performed using the Carl Zeiss OPMI1 operating microscope which has no co-axial illumination. The surgical technique consisted of a fornix-based conjunctival flap with haemostasis secured by wet field cautery. With a limbal section into the anterior chamber and the use of intracameral viscomet, can opener anterior capsulectomy 
Table 1 Patient outcome: uncorrected vision before surgery and 2 days later at discharge in the better eye of the 169 patients

\begin{tabular}{lll}
\hline Category of visual acuity & $\begin{array}{l}\text { Preoperative } \\
\text { No (\%) }\end{array}$ & $\begin{array}{l}\text { Postoperative } \\
\text { No (\%) }\end{array}$ \\
\hline 0: Normal vision $(6 / 6-6 / 18)$ & $64(37.8)$ & $76(45.2)$ \\
1: Visual impairment $(<6 / 18-6 / 60)$ & $56(33.2)$ & $85(50.6)$ \\
2: Severe visual impairment $(<6 / 60-3 / 60)$ & $8(4.7)$ & $5(3.0)$ \\
3: Blind (<3/60-PL) & $41(24.3)$ & $2(1.2)$ \\
Total & $169(100)$ & $168(100)$ \\
Not recorded & - & 1 \\
\hline
\end{tabular}

Table 2 Physiological outcome: preoperative and postoperative visual acuity in 169 operated eyes

\begin{tabular}{lllll}
\hline $\begin{array}{l}\text { Category of vision/visual } \\
\text { acuity (PH) }\end{array}$ & $\begin{array}{l}\text { Preoperative } \\
\text { No }(\%)\end{array}$ & $\begin{array}{l}\text { At discharge } \\
\text { No }(\%)\end{array}$ & $\begin{array}{l}\text { Postoperative } \\
(2-4 \text { weeks) } \\
\text { No }(\%)\end{array}$ & $\begin{array}{l}\text { Postoperative } \\
(\geqslant 6 / 12) \\
\text { No }(\%)\end{array}$ \\
\hline $0(6 / 6-6 / 18)$ & $0(0)$ & $31(18.8)$ & $46(36.8)$ & $18(54.6)$ \\
$1(<6 / 18-6 / 60)$ & $18(10.7)$ & $113(68.5)$ & $66(52.8)$ & $11(33.3)$ \\
$2(<6 / 60-3 / 60)$ & $6(3.5)$ & $15(9.1)$ & $6(4.8)$ & $1(3.0)$ \\
$3(<3 / 60-\mathrm{PL})$ & $145(85.8)$ & $5(3.0)$ & $7(5.6)$ & $3(9.1)$ \\
$4(\mathrm{NPL})$ & $0(0)$ & $1(0.6)$ & $0(0)$ & $0(0)$ \\
Total & $169(100)$ & $165(100)$ & $125(100)$ & $33(100)$ \\
Not recorded/reviewed & - & 4 & 4 & 136 \\
\hline
\end{tabular}

was performed using an appropriately bent insulin syringe needle. Nucleus delivery was by vectis and cortical clean up was by manual irrigation-aspiration with a Simcoe cannula using normal saline as the irrigating fluid.

Postoperatively, all the patients were treated with topical antibiotics, corticosteroids, and mydriatic agents.

The medical records of all the patients were retrieved for analysis of patient data, preoperative and postoperative VA at discharge and 2-4 weeks after discharge, and intraoperative and postoperative complications. Definitive postoperative refraction had not been done for all the patients, so uncorrected and pinhole acuity was recorded. The preoperative and postoperative visual status was classified using the World Health Organization (WHO) category of Visual Impairment and Blindness. The standard parameters of assessing quality or outcome of cataract surgery described by Foster ${ }^{5}$ and the WHO guidelines for monitoring the outcome of cataract surgery ${ }^{6}$ were used.

Table 3 WHO guidelines to monitor the outcome of cataract surgery

\begin{tabular}{lllll}
\hline & $\begin{array}{l}\text { Available } \\
\text { correction } \\
\text { (recommended) }\end{array}$ & $\begin{array}{l}\text { Best correction } \\
\text { (recommended) }\end{array}$ & $\begin{array}{l}\text { 125 eyes 2-4 } \\
\text { weeks after surgery } \\
\text { (pinhole acuity) }\end{array}$ & $\begin{array}{l}33 \text { eyes } \geqslant 6 \text { months } \\
\text { after surgery } \\
\text { (uncorrected) }\end{array}$ \\
\hline Gostoperative acuity & $80 \%+$ & $90 \%+$ & $37 \%$ & $55 \%$ \\
Borderline $(<6 / 18-6 / 60)$ & $15 \%-$ & $5 \%-$ & $53 \%$ & $33 \%$ \\
Poor $(<6 / 60)$ & $5 \%-$ & $5 \%-$ & $10 \%$ & $12 \%$ \\
\hline
\end{tabular}

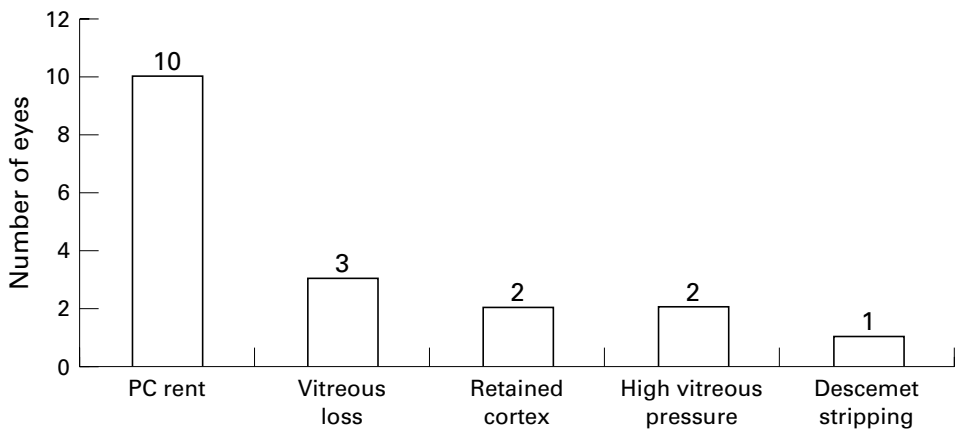

Figure 1 Intraoperative complications.

\section{Results}

A total of 175 cataract extractions were performed during the training course. The mean age of the patients at operation was 54.2 years (range 21-87); 169 patients had ECCE + PC-IOL while six patients had no intraocular lens implanted because of complications during surgery. These six patients were excluded from the analysis of visual outcome. During the follow up period three had corrected VA of 6/1-6/60 with aphakic spectacles but two of them developed posterior chamber opacification about 2 years after surgery, with a fall in vision to counting fingers $(\mathrm{CF})$. Two remained blind from the immediate postoperative period, one of whom had pre-existing long standing rhegmatogenous retinal detachment. One further patient has not been seen since discharge.

One hundred and twenty five operated eyes $(74 \%)$ were examined $2-4$ weeks after surgery while $44(26 \%)$ were lost to follow up at this time and were also excluded from the table of final visual outcome.

Table 1 shows that preoperatively 41 patients $(24.3 \%)$ were blind (VA $<3 / 60)$, while only two $(1.2 \%)$ remained so at discharge two days after surgery. Forty two of the 49 patients who were either blind or severely visually impaired were restored to useful vision.

Table 2 shows that, in the operated eyes, pinhole VA of $6 / 60$ or better was obtained in 144 eyes $(87.3 \%)$ at discharge and in 112 eyes $(89.6 \%)$ when followed up at 2-4 weeks compared with 18 eyes $(10.7 \%)$ with similar preoperative VA.

Although 145 eyes (85.8\%) were blind preoperatively, only six $(3.6 \%)$ were blind at discharge. Seven $(5.6 \%)$ of those seen at $2-4$ weeks remained blind. Only 35 patients (21\%) were seen 6 months or more after surgery. Of these, $54.6 \%$ had good uncorrected VA, 33.3\% had borderline VA, and $9.1 \%$ remained blind. Table 3 indicates that, of the 125 eyes whose pinhole VA was recorded at 2-4 weeks after discharge, $10 \%$ had a poor functional outcome of cataract surgery, $53 \%$ had a borderline outcome, and $37 \%$ had a good outcome.

Intraoperative complications occurred in 18 eyes $(10.2 \%)$ as shown in Figure 1 . The most common intraoperative complication was posterior capsular rent (PC-rent) in 10 eyes $(5.7 \%)$, which was associated with vitreous loss in three eyes. This prevented PC-IOL insertion in six eyes.

The immediate postoperative complications that occurred in 104 eyes $(59.5 \%)$ are shown in Figure 2. Seventy eight eyes $(44.6 \%)$ had striate keratopathy/corneal oedema while cortical or anterior capsular remnant occurred in 14 eyes $(8 \%)$. One eye $(0.6 \%)$ developed postoperative endophthalmitis.

\section{Discussion}

VISUAL OUTCOME

About $25 \%$ of the patients were blind and 38\% were visually impaired before surgery, while $85.8 \%$ of the operated eyes were blind before surgery. Postoperatively, however, only $1.2 \%$ of the patients remained blind. This signifies that 


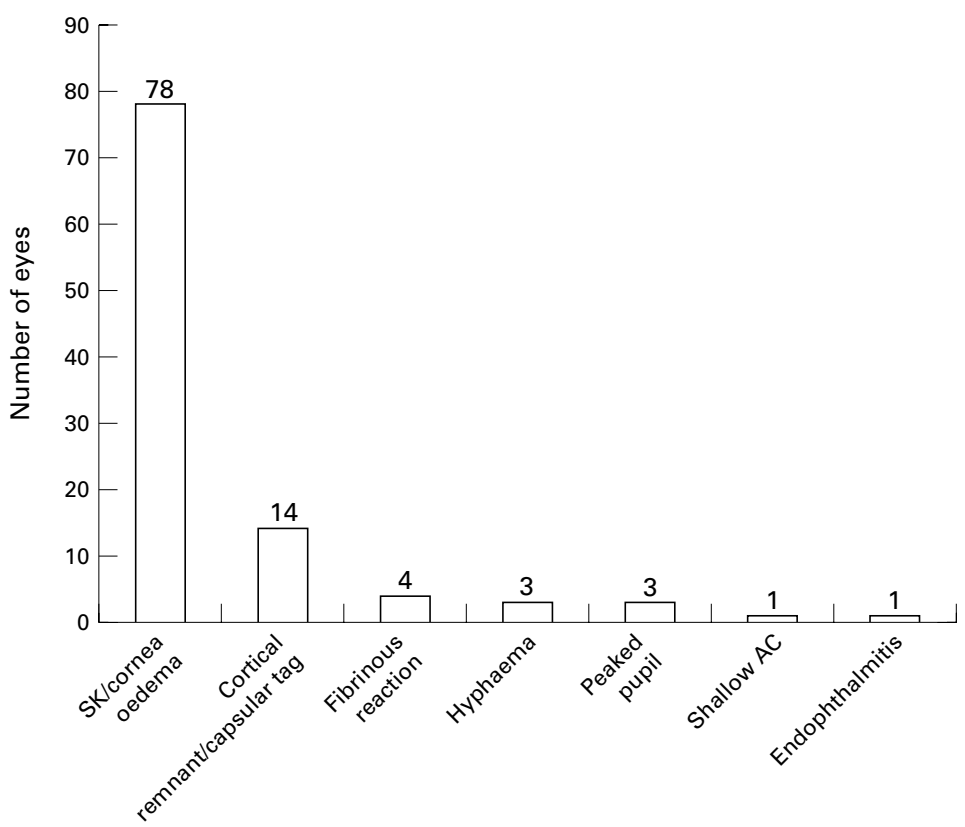

Figure 2 Immediate postoperative complications.

a considerable number of patients were visually handicapped from cataract before resorting to surgical treatment. The picture is similar in most developing African countries. In Sierra Leone $51 \%$ of patients were blind in the better eye before surgery in an evaluation of high volume ECCE with PC-IOL, ${ }^{7}$ and in Ghana all but one patient had preoperative VA of counting fingers or worse. ${ }^{8}$

Improved visual outcome in the operated eyes with PC-IOL implantation has been shown in this study. About $90 \%$ of the eyes reviewed 2-4 weeks after surgery had uncorrected VA of at least $6 / 60$. Our results compare with the results in Ghana ${ }^{8}$ where $75 \%$ had best corrected vision of better than $6 / 60$, and the South African series ${ }^{9}$ where $81.6 \%$ of 987 patients had a postoperative uncorrected vision of $6 / 24$ or better. Only about $4 \%$ had an uncorrected VA of less than $6 / 60$, which is lower than $10.4 \%$ with similar vision in our patients. In our patients uncorrected VA of $6 / 18$ or better was attained in $37 \%$ at $2-4$ weeks after surgery compared with $41.7 \%$ who achieved the same VA at 4 weeks in the series reported by Cook. In the longer term, however, about $55 \%$ of the few patients seen at 6 months had good uncorrected VA, although this is lower than the audit of ECCE + PC-IOL at Kikuyu Eye Unit ${ }^{10}$ which showed that $73.1 \%$ had uncorrected VA of $6 / 18$ or better 2 months after surgery. Almost all the patients had not been refracted for best corrected vision. Errors in A-scan biometry and keratometry, which were performed by different doctors, may have contributed to refractive error.

Based on the WHO guideline for evaluating the outcome of cataract surgery, most of the patients $(53 \%)$ had a borderline outcome and only $37 \%$ had a good outcome. This is much lower than the target set by WHO of $80 \%$ or more for a good outcome using available correction. The high rate of visual recovery means more socioeconomic productivity for the individual patients and the society at large. Ten per cent of our patients had a poor outcome with VA less than 6/60 2-4 weeks after surgery. However, VA improved between discharge and first follow up and it is expected that it would be improved further at later follow up, especially with best correction. The WHO target should be aimed at by improving surgical skills and correction of refractive errors.

Forty four patients (26\%) were lost to follow up at 2-4 weeks and more than three quarters of the patients were not seen at 6 months or later. It is presumed that the level of postoperative vision was adequate for their daily activities or that financial/geographical logistics prevented them from coming for postoperative review. The high percentage lost to follow up at this early postoperative time is not uncommon in our practice and will affect proper documentation for future reviews.

Even though most patients may be satisfied with their uncorrected pseudophakic vision, it is more rewarding to have postoperative refraction to correct any residual refractive error. The pinhole vision was used for this review because definite refraction had not been done in all the patients. The postoperative visual recovery with pseudophakia is better than with spectacle corrected aphakia. ${ }^{49}$

\section{COMPLICATIONS}

The most common intraoperative complication encountered was PC-rent in 10 eyes $(5.7 \%)$, three of which had vitreous loss. Although similar to the incidence in Finland of $5.4 \%,{ }^{11}$ this contrasts with the incidence in Aravind Eye Hospital, India where there is a large output of cataract surgery and only $1.7 \%$ of 898 eyes developed rents in the posterior capsule. ${ }^{12}$ Other African studies have reported an incidence of $10 \%$ in $\mathrm{Ghana}^{8}$ and $11.4 \%$ in Sierra Leone. ${ }^{7}$ Adejor's early experience in this hospital recorded a much higher rate of $22 \%{ }^{4}$ The lower rate in this study may be because surgeons who were already experienced in ECCE without IOL insertion performed the operations under supervision. Careful selection of patients to exclude complicated cataracts and the use of viscoelastic to maintain anterior chamber depth during anterior capsulectomy and IOL insertion also helped to reduce the chance of PC-rent. PC-rent is the major cause of failed IOL insertion, especially if associated with vitreous disturbance. Six of our patients did not have PC-IOL inserted because of this intraoperative complication. Although initial postoperative VA with aphakic spectacles was $6 / 12$ and $6 / 18$ in two patients, they subsequently developed opacification of the residual posterior chamber which has not yet been treated because of the lack of YAG laser facilities. The patient who had a preexisting rhegmatogenous retinal detachment declined surgery for financial reasons. These eyes therefore remained effectively blind, doubling the blindness rate from this training course. 
There was a high incidence of significant postoperative corneal oedema/striate keratopathy $(44.6 \%)$. Again, this is comparable to the $53.6 \%$ incidence in the Finnish series ${ }^{11}$ and was probably because the surgeons were relatively new to the technique and intraoperative manipulation was a contributing factor. The role of corneal endothelial toxicity from the use of anterior chamber irrigating fluids such as normal saline could also not be excluded.

Another postoperative complication that affected the visual outcome was cortical remnant which was recorded in $8 \%$ of the operated eyes. Retained cortex can cause lens induced uveitis and transient rise in intraocular pressure. With improved surgical skills these complications are expected to reduce.

One case of bacterial endophthalmitis was recorded $(0.6 \%)$. The eye was lost eventually because of failure to respond to topical, intravitreal, and systemic antibiotics. This incidence is similar to that reported from Sierra Leone $(0.47 \%)$, although the number of patients included in their study was much higher. ${ }^{7}$

The follow up period of 4 weeks was too short to consider any late postoperative complications that may require secondary operative procedures. Posterior capsular opacification, thought to be a common consequence of ECCE, has been found to occur less frequently in age related complete (mature) cataracts. ${ }^{13}$ If it causes significant visual loss, it requires capsulotomy, preferably with YAG laser, which is presently not available in this centre. Pseudophakic bullous keratopathy is a leading cause of keratoplasty in industrialised countries. Loss of vision resulting from corneal decompensation accounted for some of the $25 \%$ of patients with poor visual outcome in Ghana. ${ }^{8}$ Retinal detachment has a lower incidence following ECCE than with ICCE.

Although the material resources required for IOL implantation surgery are considerable, it is encouraging to realise that there is a downward trend in the cost of the equipment and consumables. There is already local production of good quality IOL in India, Nepal and Eritrea at affordable rates. Viscoelastic materials are also available at a reduced cost. These have been made readily available through assistance by some international nongovernmental development organisations (NGDOs).

Another major limitation to the widespread use of IOL implants in Africa is the lack of trained personnel. ${ }^{10}$ Many of the ophthalmolo- gists have to be retrained for conversion from ICCE to ECCE + PC-IOL. It was with this in view that the National Eye Centre, Kaduna in collaboration with Sight Savers International and Aravind Eye Hospital offered this first training course in IOL microsurgery which is to be held regularly for ophthalmologists and residents in ophthalmology. In the near future, more ophthalmologists in Africa will be skilled in IOL microsurgery.

This review shows that high quality IOL microsurgery in carefully selected cataract patients offers good visual results even in training courses. The major determinant of good visual outcome is the surgeon's skill, for which adequate training is mandatory. The surgical technique of ECCE + PC-IOL needs good surgical skills to reduce both intraoperative and postoperative complications to ensure better VA than with ICCE. Long term review is necessary to determine the outcome of this surgical technique in our environment, bearing in mind the need to treat late postoperative complications that may arise. The results of this study can also be used to compare and monitor improvements when evaluating subsequent microsurgical training courses.

The authors acknowledge the support of Sight Savers International (UK) by the provision of material resources for the course; Aravind Eye Hospital, India for providing the trainers; and the trainees who participated in this programme.

1 NPPB Secretariat. Available data on blindness. Kaduna, Nigeria: National Eye Centre, 1997.

2 American Academy of Ophthalmology. Primary intraocular lens insertion in adults: historical perspective. In: $B C S C$. Section 11: Lens and cataract. 1997-1998: 118-20

3 Ukety T. Management of cataract in Zaire. Nig $\mathcal{F}$ Ophthalmol 1997;5:30-3.

4 Adejor GO. Early experience with posterior chamber intraocular lens implantation in National Eye Centre, intraocular lens implantation in National Eye

5 Foster A. A simple method for evaluating surgical cataract services in prevention of blindness programmes. Coтmunity Eye Health 1992;10:2-5.

6 World Health Organization. Informal consultation on analysis of blindness prevention outcomes. WHO/PBL/ 98.68. Geneva: WHO, 1998

7 Cook NJ. Evaluation of high volume extracapsular cataract extraction with posterior chamber lens implantation in Sierra Leone, West Africa. Br F Ophthalmol 1996;80:698701.

8 Egbert PR, Buchanan M. Results of extracapsular cataract surgery and intraocular lens implantation in Ghana. Arch Ophthalmol 1991;109:1764-8.

9 Welsh NH. Extracapsular cataract extraction with and without intraocular lenses in black patients. S Afr Med F 1992; 81:357-60.

10 Yorston D. Are intraocular lenses the solution to cataract blindness in Africa? Br f Ophthalmol 1998;82:469-71.

11 Lumme P, Laatikainen LT. Risk factors for intraoperative and early postoperative complications in extracapsular cataract surgery. Eur 7 Ophthalmol 1994;4:151-8.

12 Natchiar G, Robin AL, Nalgirkar AR, et al. Posterior capsule tears during extracapsular cataract surgery in India. Arch Ophthalmol 1993;111:706-8.

13 Argento C, Nunez E, Wainsztein R. Incidence of postoperative posterior capsular opacification with types of senile cataracts. F Cataract Refract Surg 1992;18:586-8. 